$\mathrm{JD}$

78,7

176

Received 8 October 2020

Revised 11 August 2021

Accepted 14 August 2021

\section{"I can read, I just can't see": a disability rights-based perspective on reading by listening}

\author{
Anna Lundh \\ Libraries, Archives, Records and Information Science, \\ School of Media, Creative Arts and Social Inquiry, Curtin University, \\ Perth, Australia and \\ The Swedish School of Library and Information Science, University of Borås, \\ Borås, Sweden
}

\begin{abstract}
Purpose - The aim of the paper is to create a greater understanding of how people who are blind or vision impaired describe their use of audio-based reading technologies, with a particular focus on how they reason about whether the use of these technologies can be understood in terms of reading.

Design/methodology/approach - The study is part of the emerging research area Critical Studies of Reading and draws theoretical inspiration from Document Theory, New Literacy Studies and Critical Disability Studies. The article presents a discourse analysis of how 16 university students in Australia who are blind or vision impaired and use audio-based reading technologies describe this use in semi-structured interviews.

Findings - The participants relate to a division between 'real' reading and reading by listening, where the latter is constructed as an exception and is connected to the subject position of being blind or vision impaired. However, resistance is also noticeable, where reading by listening is constructed as something that is normal, and as a right.
\end{abstract}

Originality/value - The article is a theoretical and empirical contribution to the ongoing discussion on the use of audio-based reading technologies. It presents perspectives from the users of these technologies and argues why a specific understanding of this use is important.

Keywords Critical disability studies, Critical studies of reading, Discourse analysis, Document theory, New literacy studies, Print disabilities, Reading, Reading by listening, Talking books, Text-to-speech, University students, Vision impairment

Paper type Research paper

\section{Introduction}

The aim of this paper is to create a greater understanding of how people who are blind or vision impaired describe their use of audio-based reading technologies. These types of technologies engage hearing as the primary sense used for reading, rather than vision (as

(c) Anna Lundh. Published by Emerald Publishing Limited. This article is published under the Creative Commons Attribution (CC BY 4.0) licence. Anyone may reproduce, distribute, translate and create derivative works of this article (for both commercial and non-commercial purposes), subject to full attribution to the original publication and authors. The full terms of this licence may be seen at http:// creativecommons.org/licences/by/4.0/legalcode

The author wishes to thank the research participants for their time and willingness to share their experiences and views of their reading practices. She would also like to thank Mats Dolatkhah, Ase Hedemark, Scott Hollier, Linnéa Lindsköld, Elisa Tattersall Wallin and participants at the research seminar at the Linnaeus Centre for Research on Learning, Interaction and Mediated Communication in Contemporary Society (LinCS) for their valuable input during the preparations for and the writing of this paper; Christine Yates for her excellent help with the transcriptions of the interviews and the English editing of the manuscript; and the anonymous reviewers for their helpful suggestions.

Funding: This study has been funded by the Curtin Research Fellowship, Curtin University, Perth, Australia. 
with print or screen-based text) or touch (as with braille) (see Tattersall Wallin, 2021). They include built-in or add-on screen readers and text-to-speech tools for mobile devices, laptops and computers; talking books produced specifically for people with print disabilities; and commercially produced audiobooks. In particular, the article focuses on how people who are blind or vision impaired, reason about whether the use of these technologies can be understood in terms of reading.

People with or without print disabilities such as vision impairments and blindness are increasingly using audio-based technologies to read, and it has been suggested that these reading activities should be conceptualised as reading by listening (Tattersall Wallin, 2021). However, since the inception of talking books over a hundred years ago, there has been a discussion about whether the use of audio versions of books and other types of documents should be regarded as reading. Rubery (2016) gives a historical account of how this debate has taken shape within the blindness communities in the Anglosphere and describes how it has been based on exclusion, opposition, and conflict, and the notion that only one mode of reading can be regarded as 'real' reading. This discussion is ongoing (see Tattersall Wallin, 2021), both within and outside the blindness community. Thus, researchers wanting to contribute to a greater understanding of the reading practices of audio readers - practices that are both under-researched and under-theorised - still have to argue for the understanding of the use of audio-based technologies for reading as reading activities and reading practices.

The argument that the use of audio-based technologies for reading can be understood in terms of reading is a disability rights-based argument. It might seem paradoxical, but highlighting the audio reading practices of people with print disabilities is an endeavour toward having these practices recognised as mainstream rather than outside the norm. However, in many regards, reading by listening is constructed as an exception. For example, when considering access to published books - in countries where the production and dissemination of accessible media are relatively well-coordinated - only $5-7 \%$ of all titles are accessible to people with print disabilities (Harpur, 2017, p. 7). Whilst an ideal situation would be that all text was formatted in ways that make it accessible to everyone - no matter what tools they use for reading - the current situation is very different. However, until this ideal situation is a reality, it is important to draw attention to the various ways in which people do read, as well as to the mechanisms that prevent people from accessing text in their preferred formats. One such mechanism is how the use of audio-based reading technologies is described and understood; the view that reading by listening is not 'the real thing' may have detrimental consequences for people to whom this way of reading is a necessary means to accessing text.

In their seminal text "The Social Life of Documents", Brown and Duguid (1996) emphasise that new types of "document technologies" might entail the potential for social change, but that such changes "will be the result of a great deal of social work, conflict, coordination, and creativity, conducted around but not determined by the technology" (Brown and Duguid, 1996, "Documents, Determination, and Enabling"). This article discusses how the use of audio-based reading technologies, such as screen readers and text-to-speech tools, talking books and audiobooks, can be theoretically framed as reading. The article also presents an analysis of how people who are blind or vision impaired describe their use of these types of technologies. Thus, this article should be understood as a way of taking part in the "social work" - or social and discursive negotiation - concerning digital audio-based reading technologies.

However, the argument made is not based on an uncritical technology optimism where the challenges that people with print disabilities face are seen as possible to resolve through technologies only. Nor is it an attempt to take sides in dichotomised and normative discussions where audio is put in opposition to print or braille (see Rubery, 2016). Rather, the 
JD

78,7

argument that this study is based on is that the ways in which the use of audio-based reading technologies is described and understood by the people using them, as well as by researchers, professional groups and institutions such as libraries, publishers and educational institutions, may have an impact on whether, how, when and where people actually can read by listening.

The article is structured as follows: First, the theoretical basis of the argument is presented. This is followed by a section on the methodology of the empirical study where people who were blind or vision impaired were interviewed about their audio reading practices. Next, a discourse-oriented analysis of how participants in the study responded to a question about whether they regarded their use of audio-based reading technologies as reading is presented. This is followed by a concluding section discussing the analysis and outlining possible avenues for further research.

\section{Framing reading by listening}

This study should be understood as a part of an emerging research area called Critical Studies of Reading (see Lindsköld et al., 2020). As such, the study does not seek to define what reading 'is' in order to define what it is not. Nor will it determine whether one type of reading practice (such as reading by listening) is essentially superior or inferior to another (such as reading print or braille). Rather, the article discusses how certain reading activities and practices are understood and negotiated in a particular social and historical era (see Frohmann, 2009; Lundh et al., 2018) - and also argues for why a specific understanding of these activities and practices is important. The basis of the study is a poststructural discourse-analytical position, meaning that the focus is on "what is 'in the true', what is accepted as true" (Bacchi and Goodwin, 2016, p. 31), rather than on universal definitions of, in this case, reading. How this position is operationalised in this study is further described in the methodology section below.

While discourse analysis provides an epistemological foundation and an analytical toolbox for the study, further theoretical inspiration derives from three different but related areas that focus on various aspects of reading and disability. This includes Document Theory as developed by, among others, Frohmann (2004a, b; see also Lundh and Dolatkhah, 2016); New Literacy Studies (see Gee, 2015), and Critical Disability Studies, as it is described by, for example, Harpur (2017) and Ellis and Kent (2011). Whereas Document Theory and New Literacy Studies can help us understand and conceptualise reading practices and activities in a broad sense, a Critical Disability Studies perspective offers a rights-based perspective on reading.

In his descriptions of documentary practices - of which reading practices are a part (see Lundh and Dolatkhah, 2016) - Frohmann (2004a) presents four interconnected characteristics of such practices, namely that they are material, institutionally situated, socially disciplined and historically situated. These characteristics have implications for how reading by listening is both practiced and regarded.

Highlighting the material aspects of reading practices entails, among other things, a possibility to illustrate how the conversion from a print or screen-based text into an audio format might change some of its meaning-making potentials (Lundh and Smith, 2015; see also Francke, 2008; Tattersall Wallin, 2021). Audio-based tools for reading obviously include sound in the form of recorded or synthesised speech based on a print (or screen-based) original text. If the conversion was thought about as a process entailing a piece of neutral information that is just expressed in a different format, this difference between the original version and the audio version would not be seen as significant. However, the importance of the narrator of a text, or the quality of the synthesised speech, are concerns that have engaged audio readers throughout the history of audio-based reading formats (Getz, 2003; Mills and Sterne, 2020; Rubery, 2016; Suchato et al., 2010). 
Even though reading by listening often might seem like a solitary activity, not least in an era where the use of ear and headphones are prevalent, examining this activity from the theoretical perspective of Document Theory means that individual reading and writing activities are seen as part of and in relation to wider institutional, social and historical practices (Lundh and Dolatkhah, 2016). Thus, how the use of audio formats is regarded is not just a question of personal preferences (even though these are important) but is also a question of socially, historically and institutionally shaped expectations and traditions. The very discussion about whether the use of audio-based reading technologies can be seen as 'real' reading is based on such expectations and traditions.

To further this line of thought - that understandings of what counts as 'real' reading are tied to social, historical and institutional practices - we can turn to the research tradition of New Literacy Studies (see Gee, 2015). Central in this tradition is the identification and questioning of the so-called "autonomous model of literacy" (Street, 1984; see also Gee, 2015) according to which literacy is something universal, generic and purely cognitive that once it is acquired can be transferred from one context to another (Gee, 2015). Instead, this tradition emphasises that there are multiple types of literacies that work "together with a large number of other social factors, including political and economic conditions, social structure, and local ideologies" (Gee, 2015, p. 43). Furthermore, one of the central theorists in New Literacy Studies, Brian Street, developed a critique of the Ongian distinction between oral and literate societies and emphasised how "[1]iteracy practices are always embedded in oral uses [...]" (Street, 1995, p. 157). Thus, rather than seeing oral and written language as separate forms of communication, the relationships between the two are brought to the fore (Street, 1995). Therefore, when taking this view, reading by listening can indeed be seen as a valid literacy or reading practice that includes a structured combination of written and oral language. This perspective also means that reading by listening is not seen as an isolated activity, but performed in relation to social, historical and institutional norms and practices, some of which construct reading by listening as something else than 'real' reading, perhaps not least because of long-held understandings of written and oral communication as being essentially different.

The above line of reasoning - where ways of speaking about the use of audio technologies for reading is seen as having implications for actual readers - has also drawn inspiration from Critical Disability Studies. Research in this tradition has identified, problematised and questioned discourses of disability. Harpur (2017, pp. 32-38) describes how Critical Disability Studies started with the identification and critique of the medical model of disability in which people with disabilities are described according to a deficit approach, in other words, as nonable-bodied people such as 'the blind' or 'the dyslectic'. The social model of disability grew out of this critique and emphasised "the social processes and policies that cause disablement" (Harpur, 2017, p. 35). Researchers that subscribe to this model argue that people with impairments are disabled by an ableist world (Ellis and Kent, 2011, pp. 3-4). Thus, according to this model, print disabilities are not caused by people's impairments (e.g. vision or mobility impairments, dyslexia); they are caused by print or screen-based documents being published in inaccessible formats.

In addition, as mentioned earlier, the theoretical perspective of Critical Disability Studies also highlights how audio reading practices are regarded as exceptions. In the case of book publishing, reading by listening is seen as an exception in a legal sense. For example, talking books that include recorded versions of published written text are specifically designed for people with print disabilities, unlike commercial audiobooks produced for the general public. In many parts of the world, libraries, government authorities and non-profit organisations produce and distribute digital talking books by way of exceptions in copyright laws that permit works to be reproduced in formats accessible for people with print disabilities (Harpur, 2017; Lundh and Johnson, 2015). This is also the case for many e-books; even though it is technically possible to make standard e-books accessible for people with print disabilities as 
$\mathrm{JD}$

78,7

180

soon as they are published, this is not yet standard practice (Harpur, 2017). Instead, people who use assistive technologies and who want to read e-books published in inaccessible formats need to have the original text converted to an accessible format, just as they would need with print books.

Reading by listening is also constructed as an exception in many social and institutional practices. For example, for university students with disabilities, there is often a large amount of extra work, organisation and self-advocacy required to succeed in their studies, compared to their "able-bodied" peers (cf. Bagga-Gupta et al., 2016). Focusing particularly on the provision of accessible formats for students with print disabilities at Australian universities, Harpur and Loudoun (2011) show how institutional practices in combination with the (in) action(s) of some publishers led to delays in the provision of required readings to these students. In turn, these delays created substantial problems for students with print disabilities to meet assessment deadlines and subsequently complete their courses.

Thus, to overcome the disablement that, for example, the publication of inaccessible books or the slow speed of converting materials cause for university students, there are profound changes needed. Many of these changes are practical, technological and economical in nature. However, making documents accessible - or non-disabling - is not just a technological question, it is also a social, discursive and institutional one.

\section{Methodology}

The empirical material analysed in this article was produced between September 2018 and June 2019. This material formed part of a larger study that sought to create a greater understanding of the reading practices and activities of university students who are blind or vision impaired and users of audio-based reading technologies. As a whole, the study builds on the basic premise of library and information science user studies, namely that the practices of a particular user group requires the involvement of the actual users (e.g. Case and Given, 2016). In relation to the use of audio-based reading technologies by people who are blind or vision impaired, studies that focus on the everyday use of these tools are still quite rare (see Lundh, 2017).

The empirical material consists of recordings and verbatim transcripts of 16 semistructured interviews. The interviews were conducted by the author via phone and (video) call services such as Skype and Messenger and lasted around an hour. The participants were recruited through an extensive recruitment process that included the distribution of recruitment flyers through departments providing disability services for students at Australian universities, snowballing, communication via professional contacts and networks of the author and a research assistant, and the author's participation in a radio programme broadcasted by Vision Australia (an NGO providing services to people who are blind or vision impaired in Australia). All participants at the time of the interview, had a vision impairment, were or had recently been studying at a university in Australia and were users of audio-based reading technologies. The group was diverse in terms of country of birth, age and type of subject studied. While some of the participants were born with a vision impairment, others had lost (some of) their vision at a point in their lives. To protect participant confidentiality, details on the type of subjects studied, age, country of birth, gender, and other information that could reveal their identity have not been disclosed. Each participant was assigned a letter as a pseudonym, where Participant $A$ was the first person to be interviewed, and Participant Q the last. To avoid confusion with the "Interviewer" in the transcripts, no participant was assigned the pseudonym of Participant I [1].

The interviews revolved around the participants' use of text-to-speech tools, digital talking books and other audio-based tools for reading, especially in relation to their university studies, although leisure reading was sometimes discussed to provide a point of comparison. 
The focus of the analysis is the participants' responses to one question that was asked in every interview, namely variants of "Do you consider listening to literature and other written information to be reading? Why/why not?". While most interview questions concerned the participants' reading activities on a practical level (how, when, and where they read, how they found materials to read for their studies, etc.; the analyses of these responses will be reported elsewhere), the question in focus was formulated in a more discursively oriented manner and was concerned with assumptions about reading (see Darnton, 1986, pp. 15-16; Brinkmann and Kvale, 2015, pp. 258-262). In some instances, responses to this question also emerged in other parts of the interview. Where this occurred, such responses were included in the analysis.

The analysis illustrates how the participants take part in an ongoing discursive and social negotiation of understandings of reading by way of listening. It is informed by concepts developed within Foucauldian poststructural discourse analysis, namely dividing practices, subjectification and objectification processes, and resistance (Bacchi and Goodwin, 2016). The concept of dividing practices describes discursive practices that produces "differentiation and subordination" (Bacchi and Goodwin, 2016, p. 51) between subjects - or groups - and objects - or terms - such as desirable readers and desirable reading vs nonreaders and non-reading (Lindsköld et al., 2020). Relevant to the following analysis is the division between 'real' reading/reading by listening, sighted people/people who are blind or vision impaired and sight/blindness. However, resistance (Bacchi and Goodwin, 2016, p. 50) towards these divisions are also present in the interviews, illustrating how other subject positions and objects are possible.

\section{Analysis}

In this section, the analysis of the interview responses is presented in four subsections. The analysis focuses on how the participants expressed various understandings on whether listening to texts could be regarded as reading. The analysis shows how the participants reasoned and built their arguments when discussing this question with the interviewer and how their statements produce dividing practices, subjects and objects related to reading by listening. The first subsection illustrates how the participants' responses to the interview question about reading by listening are constructed and co-produced in the interviews rather than being determined in advance. The second subsection shows how a dividing practice between 'real' reading/reading by listening appeared in the interviews. The third subsection illustrates how this dividing practice produces subjects - sighted people/people who are blind or vision impaired - and objects - namely sight/blindness. In the final section, examples of resistance against these dividing practices, subject positions and objects are presented.

\section{Conversations about reading by listening}

The first subsection highlights how the interviews are understood as conversations around reading by listening. This is demonstrated through an analysis of three excerpts from the same interview.

An important aspect to consider when analysing the interviews is that even though they revolved around the participants' use of text-to-speech technologies, talking books, audiobooks, etc., all participants talked about other forms of reading that they engaged in as well. While some participants talked about reading braille, other participants explained how they used their limited vision to read, for example, large print or by using a magnifier. One participant mentioned that they used three modes of reading - reading by listening, reading using braille and reading using print. Often different formats and modes of reading were described as being used for different purposes. An example of this - that different types 
$\mathrm{JD}$

78,7

182

of formats were seen as useful for different tasks and purposes - is the following excerpt where Participant $\mathrm{E}$ describes reading using braille as more useful than audio-reading if they want to memorise what they have read:

Interviewer: So tell me more about ... you choose audio if you are going skim read, but if you are going to immerse yourself, you prefer braille?

Participant E: Yep. Yep.

Interviewer: So what types of things do you want to immerse yourself in?

Participant E: So if I'm reading a journal article, like an actual piece of research. If I really want to actually have that stick in my head, I'll read it in braille.

Interviewer: Yeah.

Participant E: [...] I don't know, if I just read things in audio I'll forget them after a while. The longevity of the memory is more likely to be if I actually read something in braille. And I don't know why that is. I guess it's along the same principles of if you are reading in print versus if you were listening to something. It would be interesting to see if there was a correlation ... whether similar areas of the brain are being activated if you like. If you are reading, because you are still reading whether it's braille or it's print, it's still reading it, versus audio, that audible learning versus the visual ... the right-left brain thing.

$[\ldots]$

So If I actually need to remember it, I physically read it.

In addition to the descriptions of how different modes of reading are useful for different tasks, two analytical points can be made in relation to the excerpt above. The first point is that Participant E, in this part of the interview uses the expression "read things in audio". The second point is the description of braille and print as similar modes of reading, whereas listening to text is something else. Following up on the first analytical point - that listening to text is talked about as "reading" - in an excerpt from a later point in the same interview, participant E explains that even though their experience of listening to a text does not feel like "physically reading", they would still use the term reading to describe the activity when talking about it:

Interviewer: [ . . . But still, you do listen to text, do you consider that to be reading?

Participant E: No actually.

Interviewer: No?

Participant E: No. I don't think I do on a lot of levels, because I'm not doing it, someone else is. Or something else is. Whereas if am physically reading it, I am reading it.

Interviewer: Yeah.

Participant E: I mean it is reading, but it's not the reading in the sense of ... oh I suppose you are ... in the sense that you are carrying out an activity that's soaking in that information in that you are listening. But there is something about physically reading. I'm wondering if it's similar to ... I've often said to [a family member] 'Oh I should get you a Kindle' and they said 'no I like to pick up a physical book'.

Interviewer: $\mathrm{Hm}$.

Participant E: And it think it's a similar thing. Reading audio . . . but no I actually like to physically read, physically read what's in front of me. 
Interviewer: But you would say that you read a document even if you've listened to it?

Participant E: Yes.

Interviewer: Even though it doesn't feel like real reading to you in a way, you would still use the verb read?

Participant E: Yes I would.

Describing listening to texts as "reading" in everyday conversation was something that several participants mentioned. The above excerpt also shows how the response to the question on what 'counts' as reading could vary within one single interview, depending, for example, on the kinds of text genres, contexts or other modes of reading that were discussed. Further on in the interview, Participant E reflects on how participating in the interview made them discuss and think about reading in new ways:

Participant E: Yeah. I wouldn't classify me reading my mail as reading my mail, because I've OCR'd [using Optical Character Recognition] it, which is really interesting. And I haven't actually thought about that until now. Yet I would classify reading a book in audio, or reading a journal article in audio or something like that as reading, but I never really thought about reading my mail as actually reading. Interesting.

Collectively the three excerpts highlight that the analysis does not concern the individual participants' views of the topic as if these views were settled before the interview and just simply presented for the interviewer. Nor do the interview excerpts represent categories such as "yes", "no" or "possibly" responses (see Potter and Wetherell, 1987, p. 173). Instead, the analysis shows how the participants reason and build their arguments when discussing the issue with the interviewer and how their statements produce dividing practices, subject positions and objects related to reading by listening. Following up on the second analytical point in relation to the first excerpt from the interview with Participant $\mathrm{E}$ and the statement "If you are reading, because you are still reading whether it's braille or it's print, it's still reading it [. . .]", a dividing practice between 'real' reading and reading by listening is visible. How this division is produced throughout the interviews is further discussed in the following subsection.

\section{'Real' reading/reading by listening}

In a sense, a basic premise for this study is that reading by listening is constructed as different from other types of reading. Unless reading by listening was seen as something in particular, the interview question "Do you consider listening to literature and other written information to be reading? Why/why not?" would not be comprehensible. This subsection focuses on how the division between 'real' reading and reading by listening takes shape in the interviews and explores some of its effects.

Some participants stated that they were well aware of discussions within the blindness community about whether the use of audio technologies should be regarded as reading and articulated views on this matter in relation to these discussions. One example of this is the following excerpt from Participant B:

Interviewer: If you listen to text or information or literature ... if you listen, do you consider that to be reading?

Participant B: Yes I do. There's actually a book if you've read. . . there's a book called "The Untold Story of the Talking Book".

Interviewer: Yeah I've read that.

Participant B: You've read that?
"I can read, I just can't see" 
$\mathrm{JD}$

78,7

184

Interviewer: $\mathrm{Mm}$.

Participant B: Yeah I know. I found that was a fascinating book.

Interviewer: Yes I thought so too. It was one of the better ones I've read lately.

Participant B: But it was interesting because it didn't deal with the actual history of the technology ... it talked a little bit about that ... but it was more about the attitudes, and I guess ethnographic or something [... . So I found that really fascinating. But yes, you know I consider it reading, and I know some people don't consider it reading, but it's not reading in the same way as reading braille.

Interviewer: No? Tell me about that.

Participant B: It's an information method. So for me it's reading, yes, but it's not the same.

In this excerpt, Participant B refers to "The Untold Story of the Talking Book" (Rubery, 2016) cited in the introduction of this article - where the history of parts of the debate on audio reading in the blindness community is dealt with, as well as "other people", to illustrate the position that the use of audio-based reading technologies should not be regarded as reading. But Participant B explains that their own position is to understand this use of audio-based reading technologies as reading. Thus, whilst Participant $B$ does describe their own use of audio as one mode of reading, they do this in relation to the historical division between 'real' reading and reading by listening. A similar position can be found in the following excerpt from the interview with Participant $G$ who refers to discussions within the blindness community on the matter and states that they personally know people who are blind or vision impaired who might not regard listening as reading - or at least do not use audio as a method of reading:

Interviewer: [...] Do you consider listening to literature and other written information to be reading?

Participant G: I do. Yeah. I do.

Interviewer: Do you think it's a strange question?

Participant G: No, I don't, because there's a huge debate among . . in our community . . . because I know of people who will only read braille, they won't touch audio. But for me, particularly with study it's about efficiency. And in my case, if you want to read things quicker, then you have to read it in audio. But if you wanted to have a ... like memorising stuff, then I would read braille.

Thus, in both excerpts, the view of the use of audio-based reading technologies as being reading is discussed in relation to a historical and current division between 'real' reading and reading by listening. Resistance towards this division is also seen in the excerpts, as reading by listening is described as one mode - of several modes - of reading.

However, in some of the interviews, reading by listening is constructed as subordinate to 'real' reading (see Bacchi and Goodwin, 2016, p. 51). One example of this is when Participant J explains that using a screen reader with a synthesised voice could be regarded as reading because it tends to bore people:

Participant J: [ . . ] But I think we can still consider it as reading because we listen to music, we listen to speech, but for literature, even though we use our ear, we still read. Because it's monotone information, if we listen to speech it has the written, it has the up and down intonation. But for this screen reading technology, it's very monotone sometimes. You feel so bored ... like people when they read they feel bored.

Interviewer: Yes. I understand. So it can be as boring as reading with your eyes is that what you are saying? 
Participant J: Yes. [laughter]

In this excerpt, reading by listening is said to resemble "reading with your eyes" as it is just as "boring". Thus, reading by listening could be said to be defended in this statement as it is described as something that requires some hardship, just as 'real' reading.

Another example of the dividing practice between 'real' reading and reading by listening, where the former is seen as something that requires a certain level of difficulty, is provided in the following excerpt. In this example, Participant $\mathrm{P}$, who had started to use audio fairly recently, explains how they used to think of reading by listening as reading. However, a comment from another person who was blind or vision impaired and who did not think of listening to a text as reading made them question their own view:

Participant P: [.. . ] And I said 'Oh gosh, yeah I'm not reading' and now I kind of feel like I'm only half doing a job if you know what I mean? I don't know, I consider it . . . yeah cause reading really is eyeballs, but there is no other way for me to explain it. So when I tell people they'll say do I read, and I say 'Oh yeah I'm reading such and such at the moment', actually I don't read it, I listen to audiobooks. So I think I don't consider it in that case.

\section{Interviewer: No?}

Participant P: I think I mean used to and then I got called on it a couple of times [laughter], cause I've been listening to audiobooks for about two years now, probably actually three years because it was about a year prior to uni, yeah. I don't know. I feel like maybe I self-stigmatise or something.

Interviewer: [laughter] Yes. So you would say to people that 'I'm reading this book, I've read this book' but when you are doing the activity do you think about it as reading, no?

Participant P: Yes, yes I do. So while I'm doing it, yeah I consider I'm reading.

Interviewer: So what's the self-stigmatising thing then?

Participant P: I don't know! I don't know! It's a different way of learning or understanding a topic. I don't know. Maybe it's like ingrained cultural values where I think that reading is sitting down reading a hard copy book, it's not listening to you know something you do on the radio, for the radio.

\section{Interviewer: Yeah.}

Participant P: Yeah I don't know. I actually learn more when I'm listening to something now than I do when I'm reading it with my eyeballs.

While Participant $\mathrm{P}$ says that they understand texts better by listening to them rather than reading them with their eyes and personally sees the activity as reading, comments from other people where Participant $\mathrm{P}$ "got called on it" - has led to them framing reading by listening as "half doing a job". But Participant $\mathrm{P}$ also ponders upon whether this can be seen as a way to "self-stigmatise" because of "ingrained cultural values" about reading where "reading really is eyeballs". Thus, Participant $\mathrm{P}$ describes that reading by listening can be seen as a way of 'cheating', as 'real' reading entails some level of effort that reading by listening is not seen to involve.

In this subsection, the division between 'real' reading and reading by listening has been explored along with how the latter is constructed as subordinate to the former. In the next subsection, the effects of this dividing practice are explored in terms of subject positions and objects.

\section{Subjectification and objectification processes}

The division between 'real' reading and reading by listening in the interviews produces different subject positions and objects, namely the subject positions sighted people/people who are blind or vision impaired and the object sight/blindness or vision impairment where
"I can read, I 
$\mathrm{JD}$

78,7

186

the former is constructed as 'the norm' and the latter as 'an exception'. For example, Participant A, who has learnt to use audio as a means of reading as an adult due to vision loss, states:

Participant A: [...] and I think of it as reading.

Interviewer: Yeah?

Participant A: Yeah.

Interviewer: Are you surprised by that question?

Participant A: No, not as such, because when you're not visually impaired, it doesn't really occur, but it's only by virtue of the fact that I've actually had to readapt myself, cause I actually think in terms of "this is reading", because I'm listening to a story, it's still reading.

In this excerpt, Participant A highlights that reading by listening - and the question about whether it could be seen as reading - is tied to the subject position of being blind or vision impaired. A similar line of reasoning is put forward by Participant F:

Interviewer: [.. . ] So I ask all participants in this study whether. . . do you consider listening to literature and other written information to be reading?

Participant F: Well I think it is. That's an interesting question Anna. I believe because I can't see I think it is a form of reading. But I still fully believe, that in order to take in what you are reading, I would actually argue that it would be good to have the format in braille. Because the reason I say that is when you are reading something with your fingers, as opposed to when you are listening to something ... when you are reading with your fingers, just like someone who is sighted, you get to pick up on grammatical errors, you get to pick up on spelling mistakes. So in some ways it's really good, it is a form of reading. But I would say that when you are reading with audio, especially with JAWS [a screen reader], it's a form of speed-reading. So it's very fast and very quick.

Interviewer: Yes.

Participant F: Whereas I think when you are reading something with your fingers, in braille or whatever, you get to really absorb the text if that makes sense?

Interviewer: Yes, yes. It really does. But you would still call ...?

Participant F: Oh yeah, quote, unquote, 'reading' definitely.

Interviewer: Yes and in everyday terms you don't differentiate sort of if someone asks you 'have you read this?' or 'I'm going to read this', you would use the term reading?

Participant F: I would yes.

Here, reading by listening is described as being reading because of Participant F's vision impairment, "I believe because I cannot see I think it is a form of reading". Furthermore, in this excerpt, reading by listening is also contrasted to reading braille, which is described as the equivalent of reading print for a sighted person. Thus, reading by listening is again described as something else than 'real' reading whether this 'real' reading is reading print or reading braille.

Another example of how reading by listening can be regarded as reading in relation to the subject position of being blind or vision impaired is illustrated in the interview with Participant L. At one point during the interview Participant L clearly stated that taking part of text via audio is not reading - at least not for them personally:

Interviewer: No. So you would say that you've read a book that you've listened to, but do you see the actual act of doing it as reading? 
Participant L: No. No. Definitely not.

Interviewer: No.. just can't see”

Participant L: No I don't.

Interviewer: No.

Participant L: There is a clear delineation for me and I cannot bridge it.

Participant L had only recently started to use audio as a means of reading due to a substantial loss of vision. Later in the interview, they described how the experience of taking part of text via audio was changing for them and that their brain - something the participant brought up in the interview without being prompted - seemed to adapt to this new mode of reading. Furthermore, Participant L highlights that for people with congenital blindness, reading by listening is a standard way of reading:

Interviewer: So you feel that you are developing your reading?

Participant L: My neural pathways definitely. Definitely changing. I can definitely say that. It's been slow, it's been frustrating, but there is a definite sense.

Interviewer: Yeah.

Participant L: Yeah a definite sense. And I know that I can trust that process because I know about neural plasticity and I know that you can do that. And I know I have the capacity to do that but I'm only experiencing it now.

Interviewer: Yeah. Yeah. So maybe I should ask you the question about whether it's reading again in a few years' time?

Participant L: [laughter] Yes! Yes! By that point in time I would imagine that I would be saying yes, because my auditory would be taking over my visual. So I'm sure that that would be a'8yes' response in a few years' time. I mean because it is. I mean look, people that were born blind, they use that capacity. And if you give them sight, by doing any surgical procedures, or teaching them to see, they would have the same if it was the opposite way around. It's still their neural pathways would do stuff, there's no doubt about it. I can definitely feel it.

In this excerpt, the argument is that reading is something carried out in the brain and that the sense used for reading - by using sight or by using hearing - is not what defines what reading is. However, the method of reading is tied to different subject positions where - just as in the previous examples - the subject position of being blind or vision impaired is a prerequisite for reading by listening.

\section{Reading by listening as normal}

Whilst dividing practices around 'real' reading/reading by listening, sighted people/people who are blind or vision impaired, and sight/blindness or vision impairment can be found in the interviews, forms of resistance challenging these divisions are also apparent. For example, Participant $\mathrm{C}$ states that reading by listening is not anything that is unusual or outside the norm:

Interviewer: [. . .] So if we talk about listening to literature and other types of written information, you talk about Facebook and emails and things as well, do you consider that to be reading as well, when you listen?

Participant C: I guess it's reading ... yeah.

Interviewer: Yeah? Can you tell me more about that? Why is that? 
$\mathrm{JD}$

78,7

188

Participant C: Do you mean why would I consider that reading?

Interviewer: Yeah, cause some people say 'oh definitely not', so I'm just curious.

Participant C: I guess it's just because it's my mode of reading. I don't consider it to be different.

Interviewer: No? I hope you don't mind that question, it's just that I'm curious.

Participant C: No, no.

Here, Participant C's response "I guess it's just because it's my mode of reading. I do not consider it to be different" prompts the interviewer to follow-up and ask if the question itself made them uncomfortable. Thus, in this excerpt, the interview question about whether reading by listening could be regarded as reading is seemingly less relevant than in several other interviews.

Another example is an excerpt where Participant B, quoted earlier in relation to the historical debate on reading by listening, was prompted later on in the interview to follow up on their response to the question on whether the use of audio-based technologies for reading could be regarded as reading:

Interviewer: And you said there's no question that it's reading, so what's your argument for that, I'm really interested?

Participant B: What, you mean that I think it's reading?

Interviewer: Yeah. Cause some people would argue that no it's not.

Participant B: Yeah I know. But that's coming from a perspective of the eye-gate visual reading paradigm.

Interviewer: Yeah.

Participant B: I mean that is where it is coming from.

Interviewer: $\mathrm{Mm}$.

Participant B: Because it's still information, it's still an enjoyable experience. That's why even listening to an audio play is like listening to a book, sort of. I mean it's not, it's different, it's like going to the theatre, but without being able to look at it.

Interviewer: Yeah.

Participant B: I still see them as reading. It's just that it's not the same.

Interviewer: No?

Participant B: No. That's about all I can explain I guess.

Interviewer: Yeah.

Also in this excerpt, the interview question about whether reading by listening could be regarded as reading is challenged. Here, Participant B argues that the understanding of the use of audio-based technologies for reading as something else than reading is based on "the eye-gate visual reading paradigm". Here, the subject position of being blind or vision impaired is not tied to the division between 'real' reading/reading by listening. Instead, the "paradigm" where reading is constructed as something that necessitates sight is questioned. A similar argument is made by Participant $\mathrm{D}$, who responds that reading is related to their ability to interpret written text, rather than their method of doing it:

Interviewer: [...] a question I ask all participants, is whether ... do you consider listening to literature and other types of written information as reading? 
Participant D: Yes.

Interviewer: Yes. Could you expand on that do you think?

Participant D: Do I consider it reading? Yes. Well like if someone said that I couldn't read, that's not accurate, I can read, I just can't see.

Interviewer: Yes.

Participant D: I think I'm quite a competent, intelligent person, so I don't think it would be accurate to say that I'm illiterate.

Interviewer: No.

Participant D: If you provide the information to me in the formats that suits me then I can interpret it myself.

What is also pronounced in the response from Participant $\mathrm{D}$ is the importance of being able to access documents in useful formats. Thus, the ability to read is not only seen as a matter of individual capability but also a matter of not being disabled by the lack of accessible texts. Again, the division between 'real' reading/reading by listening in relation to the subject position of being blind or vision impaired is challenged and opportunities for different understandings are made possible.

\section{Discussion and conclusion}

The aim of this paper is to create a greater understanding of how people who are blind or vision impaired describe their use of audio-based reading technologies, with a particular focus on how they reason about whether the use of these technologies can be understood in terms of reading.

The discourse-oriented analysis of the interviews shows that there is not one self-evident response to the question of whether the use of audio-based technologies for reading is regarded as reading by the study participants. Rather, the analysis illustrates how the participants use different "accounting resources" (Potter and Wetherell, 1987, p. 164) or discursive tools when they respond to this question, and that their responses vary in relation to context, that is, the context that is the actual interview and the context of their use of audiobased reading technologies. In different ways, the participants relate to the division between 'real' reading and reading by listening, where the latter is constructed as an exception, something else than 'real' reading, and connected to the subject position of being blind or vision impaired. In other words, the analysis illustrates that the historical debate on whether reading by listening should be regarded as reading (see Rubery, 2016) is still in progress and something that people who rely on audio-based reading technologies for their studies and everyday lives are conscious of. However, resistance towards the social and discursive construction of reading by listening as an exception is also noticeable in the interviews, where the interview question is challenged by the participants, and reading by listening is constructed as something that is normal and as a right.

Whilst the article does not claim to conclusively define what reading is, the analysis supports the theoretical argument that reading by listening can be constructed as a reading activity alongside other modes of reading, such as reading print or reading braille. It also highlights how maintaining that the use of audio-based reading technologies is not reading marginalises the experiences and positions of people that engage in these practices. Furthermore, such an argument contributes to the continuance of disabling practices, of, for example, libraries, publishers and educational institutions. Thus, to recognise, conceptualise and study the use of audio-based reading technologies as reading could be one small but 
JD

78,7

important step towards non-disabling social and institutional practices, where reading by listening is constructed as a right, and not as an exception.

This article has focused on the social and discursive construction of reading by listening in relation to blindness and vision impairment. Whilst the empirical material analysed involved descriptions of the participants' use of audio-based reading technologies, the analysis focussed on assumptions about reading. Yet to explore in further research is the actual use of audio-based technologies for reading in educational, workplace or leisure settings, and how this use constitutes a part of and creates specific reading practices.

\section{Note}

1. The study was approved by the Curtin University Human Research Ethics Committee (HREC number HRE2018-0502).

\section{References}

Bacchi, C.L. and Goodwin, S. (2016), Poststructural Policy Analysis: A Guide to Practice, Palgrave Pivot, New York, NY.

Bagga-Gupta, S., Messina Dahlberg, G. and Winther, Y. (2016), "Disabling and enabling technologies for learning in higher education for all: issues and challenges for whom?", Informatics, Vol. 3 No. 4, doi: 10.3390/informatics3040021.

Brinkmann, S. and Kvale, S. (2015), InterViews: Learning the Craft of Qualitative Research Interviewing, 3rd [updated] ed., Sage Publications, Los Angeles.

Brown, J.S. and Duguid, P. (1996), "The social life of documents", First Monday, Vol. 1 No. 1, available at: https://firstmonday.org/article/view/466/387 (accessed 18 February 2013).

Case, D.O. and Given, L.M. (2016), Looking for Information: A Survey of Research on Information Seeking, Needs, and Behaviour, 4th ed., Emerald, Bingley.

Darnton, R. (1986), "First steps toward a history of reading", Australian Journal of French Studies, Vol. 23 No. 1, pp. 5-30.

Ellis, K. and Kent, M. (2011), Disability and New Media, Routledge, London.

Francke, H. (2008), (Re)creations of Scholarly Journals: Document and Information Architecture in Open Access Journals, Valfrid, Borås.

Frohmann, B.P. (2004a), "Documentation redux: prolegomenon to (another) philosophy of information", Library Trends, Vol. 52 No. 3, pp. 387-407.

Frohmann, B.P. (2004b), Deflating Information: From Science Studies to Documentation, University of Toronto Press, Toronto.

Frohmann, B.P. (2009), "Revisiting 'what is a document?", Journal of Documentation, Vol. 65 No. 2, pp. 291-303.

Gee, J.P. (2015), “The new literacy studies”, in Rowsell, J. and Pahl, K. (Eds), The Routledge Handbook of Literacy Studies, Routledge, New York, pp. 35-48.

Getz, I. (2003), "What do blind people want from talking books?", paper presented at World Library and Information Congress: 69th IFLA General Conference and Council, Berlin, 1-9 August 2003, available at: https://archive.ifla.org/IV/ifla69/papers/074e-Getz.pdf (accessed 6 August 2020).

Harpur, P.D. (2017), Discrimination, Copyright and Equality: Opening the E-Book for the Print-Disabled, Cambridge University Press, Cambridge.

Harpur, P.D. and Loudoun, R. (2011), “The barrier of the written word: analysing universities' policies to students with print disabilities", Journal of Higher Education Policy and Management, Vol. 33 No. 2, pp. 153-167.

Lindsköld, L., Hedemark, A. and Lundh, A. (2020), "Constructing the desirable reader in Swedish contemporary literature policy”, Culture Unbound, Vol. 12 No. 2, pp. 256-274. 
Lundh, A.H. (2017), Användning av tillgängliga medier: En forskningsöversikt. [The Use of Accessible Media: A Literature Review], The Swedish Agency for Accessible Media, Johanneshov.

Lundh, A.H. and Dolatkhah, M. (2016), "Reading as dialogical document work: possibilities for library and information science", Journal of Documentation, Vol. 72 No. 1, pp. 127-139.

Lundh, A.H. and Johnson, G.M. (2015), "The use of digital talking books by people with print disabilities: a literature review", Library Hi Tech, Vol. 34 No. 1, pp. 54-64.

Lundh, A.H. and Smith, B. (2015), "Two King Lears: the meaning potentials of writing and speech for talking books", Proceedings from the Annual Meeting of the Document Academy, available at: $\mathrm{http}: / /$ ideaexchange.uakron.edu/docam/vol2/iss1/6 (accessed 1 May 2016).

Lundh, A.H., Dolatkhah, M. and Limberg, L. (2018), "From informational reading to information literacy: change and continuity in document work in Swedish schools", Journal of Documentation, Vol. 74 No. 5, pp. 1042-1052.

Mills, M. and Sterne, J. (2020), "Aural speed-reading: some historical bookmarks", PMLA/Publications of the Modern Language Association of America, Vol. 135 No. 2, pp. 401-411.

Potter, J. and Wetherell, M. (1987), Discourse and Social Psychology: Beyond Attitudes and Behaviour, Sage, London.

Rubery, M. (2016), The Untold Story of the Talking Book, Harvard University Press, Cambridge, Massachusetts.

Street, B.V. (1984), Literacy in Theory and Practice, Cambridge Univ. Press, Cambridge.

Street, B.V. (1995), "A critical look at Walter Ong and the 'great divide”, in Street, B.V. (Ed.), Social Literacies: Critical Approaches to Literacy Development, Ethnography and Education, Longman, London, pp. 153-159.

Suchato, A., Pongkittiphan, T., Suntornwanitkit, S., Suesattabongkot, N. and Punyabukkana, P. (2010), "Digital storytelling book generator with customizable synthetic voice styles", Paper Presented at the 4th International Convention on Rehabilitation Engineering and Assistive Technology (iCREATe'10), Shanghai, July 2010. doi: 10.5555/1926058.1926103 (accessed 10 May 2017).

Tattersall Wallin, E. (2021), "Reading by listening: conceptualising audiobook practices in the age of streaming and subscription services", Journal of Documentation, Vol. 77 No. 2, pp. 432-448.

\footnotetext{
About the author

Dr Anna Lundh is a Docent (Associate Professor) at the Swedish School of Library and Information Science at the University of Borås, Sweden, and an Adjunct Senior Research Fellow at Curtin University, Perth, Australia. Her research interests include contemporary and historical reading practices in educational contexts; reading by listening; and discourses about reading and literacy. Her current research has two major lines of inquiry: (1) Understanding reading practices that involve audio-reading technologies such as screen readers, talking books and audio books and (2) Tracing the historical background of current discourses concerning Media and Information Literacy. Anna Lundh can be contacted at: anna.lundh@curtin.edu.au
}

For instructions on how to order reprints of this article, please visit our website:

www.emeraldgrouppublishing.com/licensing/reprints.htm

Or contact us for further details: permissions@emeraldinsight.com 